\title{
La piedra y el poema. Materiales para una memoria poética desobrada
}

\author{
2v NOelia BILli / Universidad de Buenos Aires / milcrepusculos@gmail.com \\ 2 PAULA FLEISNER / Universidad de Buenos Aires - CONICET / pfleisner@gmail.com
}

\section{Resumen}

A propósito de El sexo de las piedras, de Fernando Araldi Oesterheld, nos proponemos pensar la poesía como un modo de ejercicio de la memoria que ya no puede ser escrita y archivada para su conservación en un contenido definitivo. La máquina poética abre a otra dimensión de la memoria en donde es posible hacer jugar lo inolvidable sin reducirlo a lo memorable, pues el poeta se mueve siempre en la tensión entre el recuerdo de lo que quiere olvidar y el olvido de lo que busca recordar. Así pues, la imagen poética apuntaría a conformar una presencia espectral que, lejos de la individualización de los contenidos de la memoria, circula transformándose y transformando el mundo en su contacto. En este sentido, la opera prima de Araldi Oesterheld nos ofrece la presencia imposible de sus padres (desaparecidos durante el terrorismo de Estado de la última dictadura cívico-militar) a través de imágenes que, al decir de Blanchot, restituyen su "realidad de tierra», su «materia-emoción».

Palabras clave: poesía $\cdot$ memoria $\cdot$ desobra $\cdot$ imagen $\cdot$ desaparecidos

\section{Abstract}

Through a reading of Fernando Araldi Oesterheld's El sexo de las piedras, this article intends to think of poetry as an exercise of memory which can no longer be written and filed for its preservation in a final content. The poetic machine opens another dimension of memory where it is possible to bring into play the unforgettable without reducing it to the memorable, as the poet is always in tension between remembering what he wants to forget and forgetting what he seeks to remember. Thus the poetic image would aim to create a spectral presence that, far from the identification of the contents of the memory, circulates transforming itself and transforming the world at its contact. Therefore, Araldi Oesterheld's opera prima offers the impossible presence of his parents (who disappeared during the State Terrorism of the last civic-military Dictatorship) through images that, according to Blanchot, restore its «reality of earth», its «matter-emotion».

Key words: poetry $\cdot$ memory $\cdot$ unwork $\cdot$ image $\cdot$ disappeared for political reasons 


\section{La memoria como desobra en la experiencia poética}

La poesía, lo sabemos, ha sido una gran aliada de los procesos de la memoria de pasados conflictivos. Sin pretensiones simplistas de verdad, sin «estetizar» o hacer más digerible a través de imágenes metafóricas el horror de los pasados que nos atormentan, la poesía ha servido a los filósofos incluso para pensar lo que queda del sujeto después de Auschwitz (cfr. Agamben 1998). ${ }^{1} \mathrm{Y}$ no se trata sólo de que haya sido uno de los géneros privilegiados para testimoniar lo acaecido, como en el caso de Paul Celan o Primo Levi, sino de que en su cuerpo y su cristalización por contagio, en su estructura y modo de funcionamiento, la poesía abre una nueva dimensión de la memoria.

Así como hasta el Renacimiento la memoria se espacializó en el teatro ${ }^{2}$ y en la modernidad se interiorizó en una conciencia temporal que ayudó a constituir la historia como episteme autónoma, después de Auschwitz la memoria encuentra en la experiencia poética una dimensión en donde se vuelve posible hacer jugar lo inolvidable sin reducirlo a lo memorable, pues el poeta se mueve siempre en la tensión entre el recuerdo de lo que quiere olvidar y el olvido de lo que busca recordar (cfr. Agamben 2002:34 y 43). Y, con ello, hace surgir los recuerdos en una proliferación de imágenes que conjuran lo inefable y desestabilizan todo archivo que se profiera arconte (toda fijación de la Historia que se erija en autoridad garante del Relato). ${ }^{3}$

La máquina poética, que descalabra las certezas custodiadas por la Historia, procede en la máxima tensión y oscilación entre sonido y sentido, ofreciendo una experiencia de la lengua en la que no se trata de custodiar lo no dicho - eso que reenvía siempre a un fundamento negativo, que nos sujeta y condena al triste recorrido por una interioridad cada vez más interior en la constitución de una memoria individual — sino de asumir su absoluta medialidad material: su comunicabilidad sin residuos — esa extraña relación que las palabras, restituidas aquí a su carácter anfibio, impuro, mezcla de sonido/sentido, consiguen establecer con eso que no puede ser tematizado pero tampoco olvidado, esa mezcla, también impura, de recuerdos que no están meramente presentes pero tampoco ausentes - Por ello, la memoria en la experiencia poética no es una obra, no se construye de una vez para vigilar su completud con recelo (recordemos todas las implicancias de la exigencia de «memoria completa» en los debates argentinos acerca de la dictadura cívico-militar iniciada en 1976): la memoria es la experiencia misma de una desobra, un recomienzo que hace proliferar sonido y sentido, comienzos y finales, una potencia de hacer y no hacer (o mejor, des-hacer) que impide la pereza de un cierre. La poesía es el katechon, ${ }^{4}$ si se quiere, lo que retrasa la completud de la memoria, abriendo un inagotable movimiento de imágenes memoriales que, como sabía Warburg en relación con las obras de arte visuales, comprometen racional y emotivamente (cf. 2003).

\section{La memoria de las piedras}

El sexo de las piedras, de Fernando Araldi Oesterheld, es y no es un libro de testimonio. No lo es en el sentido tradicional que se le dio a toda esa literatura
Fecha de recepción: 22/5/2016

Fecha de aceptación: $24 / 8 / 2016$ 
de relatos en primera persona que, de diversos modos, buscó hacer frente a la imposibilidad de lo vivido durante los genocidios producidos por terrorismos de estado. El poema está escrito por un hijo de desaparecidos en Argentina durante la última dictadura cívico-militar. Un hijo cuya experiencia tiene una localización díscola en el campo de lo testimonial: en él, la memoria se relaciona con algo que no vivió, o que vive sin haber vivido y, por ello, su libro empuja las nociones de memoria, testimonio, experiencia y vida hacia un borde inestable en el cual no se oponen a ni se dialectizan con las de olvido, silencio y muerte. Antes bien, en esta serie de versos dichas nociones parecen confluir y circular en los cortes e intervalos que escanden lo acontecido en un pasado inmemorial (desde siempre ya perdido) y la inminencia de un recuerdo que nunca llega. ${ }^{5}$

¿Qué tipo de experiencia poética nos viene al encuentro aquí? Lo que leemos son poemas descarnados, minerales, mínimos, desunidos, espaciados y potentes en su fragilidad. Cadencias cansinas y temblor de los sentidos. Ciertamente, aquí se refiere en imágenes poéticas una experiencia íntima pero no personal, sin rasgos identitarios claros: una experiencia impersonal de vivencias fisiológicas, materiales, emotivas pero primordiales (ovarios de piedras, mundo sin útero, placenta desierta, leche imantada que se desarma en los huesos, posición fetal a la hora del té, un yo enfriado, un padre que se desintegra no en mi casa, una madre en cuatro abierta, etc.). Se trata de una intimidad sin interioridad, pues en ese espacio de escritura no hay adensamiento donde las imágenes se fraguarían en lo oscuro de un fuero interno, imperceptible para los otros, cual sostén de una identidad personal que se fortalece en la mismidad de su recuerdo.

El poeta se ubica en (es, se confunde con) una zona desierta pero opaca, como en la máxima exterioridad, rispidez brillante y sequedad brutal del sexo entre piedras. Podría decirse que hay una analogía estructural entre la experiencia del poeta y la del sexo de las piedras, en cuanto a la especie de intimidad que allí tiene lugar: el poeta crea un espacio neutro en el cual la opacidad esencial no se debe a lo «invisible» de una acción que se produce «a escondidas», sino al acontecimiento impersonal del encuentro con piedras y huesos que, por lo demás, no están allí. Es decir, el encuentro sólo puede producirse en un modo que no remite a la autoreflexión, que no fuerza a los involucrados a «rebotar» entre las paredes de su interior en busca de un sentido personal de la experiencia. Por el contrario, el encuentro queda caracterizado por la generación de una fuerza centrífuga que hace que tanto el poeta, como la piedra, como la escritura y el sexo se incrusten en un movimiento conjunto que los aleja de sí mismos. De allí que el poeta o los partenaires sexuales no se configuren aquí como testigos (privilegiados o no) de la experiencia —que, por lo demás, les parece invisible si no inasible o, por qué no, invivible - sino que dicho lugar es ocupado por las excrecencias involuntarias derivadas de su entrelazamiento: el lector, el hijo. Pareciera que es sobre estos que recae como un imperativo lo que Jean-Luc Nancy dijera acerca de los «testimonios» de los campos de exterminio del nazismo: ante la imposibilidad de ser experimentada, su «invisibilidad» debía ser expuesta. 
Teniendo esto en cuenta, podría decirse que El sexo de las piedras es un poema sobre la ausencia de memoria, sobre la imposibilidad de recordar lo que no se vivió y que sin embargo es inolvidable

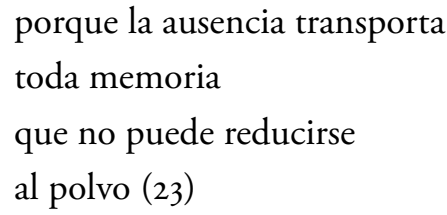

Atravesado por espacios en blanco y silencios, incluso entre sus versos se intercala a veces un «acá falta algo» entre paréntesis, literalizando el espectro de esa ausencia que no deja de aparecer. ¿Cómo pensar una memoria cuando lo «innato» equivale a lo «no nacido en lo verbal»? (I2). Al hijo le está vedada la palabra que podría significar la ausencia de la madre y del padre, pero ello, en lugar de conducirlo al silencio de las palabras lo fuerza a una anamnesis sonora y demente. Y así, escribe la ausencia con la materialidad de la palabra que marca el desdoblamiento esencial de toda noción de origen: ${ }^{6}$ el hijo regresa al lugar en que sólo permanece la "palabra cortada en dos». Cuando no hay asignación posible de significado, parece indicar el poema de Araldi, no es posible permanecer estupefacto frente al silencio. Porque el sonido asignificante mueve a construir un muro desde el exterior del sí mismo, e-mociona hacia un afuera que demoliendo la interioridad interrumpe la memoria narrativa y toma un atajo que le permite sorprender por la espalda al olvido:

en el útero no hay nombre,

hay sonido.

También la emoción demuele también

la emoción transporta también

la emoción sobra (35)

En rigor, el silencio atraviesa como un simún abrasador ${ }^{7}$ el cuerpo de la lengua, y hace que cada grano de arena del desierto del sentido se incruste allí. 
perforada la voz en un oído que implosiona,

(...)

y se verán caer

en una lluvia que se disuelve en agujas

enterradores de vacío para curar en el cuerpo los afectos (36-37)

En Idea de la prosa, Agamben caracteriza la poesía como aquella experiencia de la lengua en que se está sin palabras frente al lenguaje y al poeta como aquel infante que decide acordarse del vacío de las palabras y cumplirlo: en la total ausencia de algo que decir, la lengua se encuentra sola y abandonada, expuesta, pero sólo allí alcanza «la altura del corazón» (Agamben 2002:29). Araldi Oesterheld nos recuerda a ese nińo lejano y sin destino que escribe en un «idioma transparente,/ indiferente a ninguna seńal...», cuya escritura es «una ausencia pura que se cura según su aparición» (22), «un refugio para la materialización de las sensaciones» (46). Un hijito que conjura en la exposición del hueco de la lengua la suerte parental de piedras que respiran y de huesos desesperados por amor (7I).

La poesía, en la lectura agambeniana, se encuentra siempre entre «la incapacidad de recordar en la perfecta, amorosa adhesión al presente y la memoria que surge precisamente de la imposibilidad de este amor» (Agamben 2002:34). El poeta recuerda en el canto aquello que querría olvidar o bien olvida aquello que querría recordar en él, por ello, su fidelidad es hacia lo que no puede ser tematizado ni olvidado, su (des)obra emerge del abrazo invertido de memoria y olvido. Cuando el poeta es hablado o vivido («algo me vive», repite el poema de Araldi Oesterheld), es decir, cuando está inspirado (habitado por un dios, según la etimología griega), está sin obra: ningún yo que crea una obra, ningún reasegurante pasaje del no ser al ser, como exigía Platón de toda póiesis. En el poema, lo sabemos bien, Yo es otro y la obra es en sí misma y por sí misma des-obra, ausencia, convivencia de y con fantasmas. La palabra acontece ahora más allá de la dialéctica latencia-ilatencia - que obliga siempre a un olvido para que la memoria sea posible-, la palabra es ahora la potencia que viene después del acto.

Si esto es así, la poesía es el experimento (el juego) del lenguaje en el que podemos medirnos con lo Inmemorable que es a la vez lo inolvidable: el olvido inolvidable constitutivo del poema que busca testimoniar lo no vivido. Araldi Oesterheld construye un libro de la memoria en el que no se puede leer nada, nada cercano a un archivo que confisque lo inolvidable en el terreno menos peligroso de lo memorable, nada cercano al «nunca más» pronunciado por los presidentes de EE. UU. y Argentina en la conmemoración del 40 aniversario del golpe cívico-militar. En El sexo de 
las piedras todo es sentido que se diluye en sonidos que golpean con violencia, todo es imágenes emancipadas de referencias simples que involucran las sensaciones y los cuerpos de quienes las leen. En él, finalmente, todo es indigerible e inconfiscable por cualquier slogan que busque transformar su potencia en resignación.

$\mathrm{Si}$, como quería Dante Alighieri, la memoria es como un libro, otro libro (más difícil, más necesario) se abre en algunas obras contemporáneas en las que otra dimensión de lo memorial se pone en juego. El desafío es, para estas obras -entre ellas, la de Araldi Oesterheld-, salir de la memoria que se puede escribir y archivar de modo definitivo porque ha sido y siempre será confiscada por todo proyecto totalitario que quiera una «memoria completa». En el umbral entre lo «memorable» y lo «inolvidable» hay una zona en la que no se «tiene» experiencias (no es posible adquirirlas haciendo uso del lenguaje) sino que se experimenta con la palabra que no define, esencializa ni nomina. ${ }^{8}$ Lo experimental hace imposible la experiencia y, por ello, sólo puede suceder en el ámbito de la memoria que, desfalleciendo, crea un lugar para el olvido persistente en la superficie de las palabras. Araldi Oesterheld ubica su poema en esa zona del olvido que es inolvidable:

La escritura no simula fuerza,

es la caída,

es la aventura de una esclavitud robotizada,

ausencia pura que se cura según su aparición

porque la ausencia transporta

toda memoria

que no puede reducirse

al polvo.

Hablar, 
de un sentido

fugitivo en una zona

de respuestas:

yo,

hijo de mí mismo,

madre de mí mismo/ (22-23)

\section{La piedra y la imagen emoción}

$\mathrm{Si}$, como escribía Blanchot en La escritura del desastre, «el olvido (...) remite a formas no históricas del tiempo, a la otredad de los tiempos, a su indecisión eterna o eternamente provisional, sin destino, sin presencia», ${ }^{9}$ tal vez la escritura de Araldi Oesterheld se constituya en la sospecha de que una de esas zonas no históricas del tiempo es el lugar donde el huérfano retiene la energía de la ausencia y la convierte en la plataforma de despliegue de un polvo tan fino y tan frágil que es capaz de adherirse a las marcas y huellas mínimas que han dejado su no-madre y su no-padre en su paso ligero por el mundo. La tarea del hijo se aproxima, así, a la del forense que busca en las piedras un vestigio que no es testigo más que de la desaparición incompleta de lo que se ha olvidado.

¿se puede dejar de enloquecer? ¿el día tiene memoria?

¿se la puede desconectar?

¿aislar? ¿desnutrir?

¿arrinconar? (24) 
la memoria como náusea,

la memoria como radiación,... (รo)

Sin embargo, la memoria a la que Araldi Oesterheld refiere debe soportar la exigencia de un olvido que no actúa negativamente, en segundo lugar, olvidando lo que alguna vez fue memoria. Más bien parece señalar que el olvido allí no actúa, no hace obra (es alternativamente la náusea y la radiación). El silencio aquí no es el producto del olvido, pues el silencio se ha hecho presente antes de que cualquier memoria fuera incluso posible. Es el silencio de los desaparecidos lo que no deja de escuchar el oído del hijo y para él, entonces, el olvido puede ser la condición de base a partir de la cual comprender que olvidar no es un acto, que el olvido no es algo, sino aquello que no puede alcanzarse y por eso nos lanza al vértigo de lo inquieto que no se resuelve en un recuerdo. ${ }^{10} \mathrm{La}$ emotividad de la memoria de Araldi Oesterheld quizás se encuentra en la manera en que el olvido se aproxima a las piedras, cómo a partir de ese encuentro fortuito pero inexorable (el hueso resiste a las condiciones atmosféricas, al calor del fuego incluso) la memoria adquiere una dinámica mineral que nos brinda una noción de la imagen ligada no ya a la copia o al recuerdo de lo que no se olvida, sino una imagen hecha de lenguaje y cuya materialidad se engarza con los movimientos y conexiones que habilita.

Si bien es relativamente reciente la exclusión de la piedra del ámbito de la vida (Foucault:178), para cierto pensamiento filosófico va de suyo que la piedra es el límite (exterior) de lo animado. Así, por ejemplo, dice Heidegger: «[l]o que en general no es en el modo del ser capaz no puede tampoco estar muerto. La piedra no está nunca muerta porque su ser no es un ser capaz» (343). Sin embargo, para el campo del arte esto no parece tan seguro. Es cierto que es posible hacer una lectura «humanista» de la capacidad de afección de la piedra (en términos de ser el mero «vehículo» de emociones puramente humanas), pero hay líneas de interpretación que lo impugnan y avanzan consideraciones acerca de lo mineral que se desprenden de una manera divergente de comprender y valorar lo «inorgánico». En dichas líneas, se relativiza la importancia de la noción de «unidad totalizadora funcional» y se la pone en tensión con modos de la movilidad y la capacidad de afección que no dependen de una conciencia personal o individual. Ello conduce a un planteo disidente de la emotividad, en una ontología emancipada de la atadura antrópica que libera no sólo a la materialidad de las piedras de los reduccionismos humanísticos, sino que también abre la brecha por donde pensar la materialidad de lo que existe de una manera que no la reduzca a algún tipo de idealismo. Así, por ejemplo, lo entiende Blanchot al reivindicar el carácter mineral de la escritura y desplegar 
una ontología cuyo materialismo encuentra en dicha escritura un paradigma. En su caso, la literatura se perfila como la exposición de restos materiales, que deshacen (sin aniquilar) los intentos tanto de clausura en el significado como de construcción de sentido a partir de «bases» sólidas, aunque estén rotas o en pedazos.

De este modo, podría decirse que si la poesía construye objetos, son de una especie singular, pues lo que el lenguaje hace allí no es proveer de un espacio alternativo donde la experiencia sería posible, sino que más bien la palabra hace existir a las cosas de una manera en la cual hay en ellas una excedencia de la que no es posible dar cuenta. ${ }^{11} \mathrm{La}$ palabra, en este sentido, es una fuerza que asedia a las cosas y las expulsa de sí mismas, las expone fuera de sí, constituyendo así la exhibición de los restos, olvidados de sí. Aquí la memoria, como en Araldi Oesterheld, vuelve a pensarse bajo el modo de la «radiación», como una fuerza que atraviesa lo que es perforando invisiblemente las superficies, catalizando procesos de desagregación y a veces propiciando génesis que, por su inorganicidad, son desastrosas (Blanchot 1949:317). Si en El sexo de las piedras se escribe: "La intensidad es materia» (68), es también porque la memoria es inseparable de ésta.

En rigor, los «objetos» poéticos pueden ser llamados «imágenes». Y, quizás, en el poema la imagen se hace evidente porque no prevalece allí el intento cotidiano de enmascararla con significatividad y utilidad. Si, como piensa Blanchot, la imagen tiene una única pretensión, que consiste en restituirnos la «realidad de tierra» de lo ausente (su «materia-emoción») parece ser la piedra aquello cuya economía de dispersión, acumulación, conexión y constitución, nos permite abordarla. En efecto, en tanto "cosa», las piedras han sido consideradas como carentes de interioridad, volcadas al exterior en cada una de las capas cuyo apilamiento dan espesor a su existencia, un espesor sin profundidad. La imagen así concebida se desprende del lastre de la voluntad, conciencia y moral humanas para adquirir el peso de las afecciones que es capaz de vehiculizar, no al servicio de lo humano sino expulsando lo que toca al afuera y, por ende, haciendo de las trayectorias, el contacto y la penetración los principios de su composición. ${ }^{12}$

En este sentido, las palabras no son cápsulas huecas en las cuales viajan mensajes sino cosas que, al lanzarse, impactan, mueven, transforman y expulsan. Por eso, en este "lenguaje petrificado» (Blanchot 1980:207) sobre todo no se habla desde la evidencia de la voz viva detrás de los recuerdos (no hay recuerdo porque no hay vivientes que los recuerden), sino desde el margen de todo ello, en la zona de los que no han sobrevivido y que, sin embargo, encontramos, bajo el modo del desmembramiento:

no sobrevivirás

al incesto del sol y la luna en el paraíso desmembrado, 
madre en el sudor

inevitablemente tu expansión

dibuja las señales $(82)$

Se impugna, así, la idea de la memoria como recogimiento orgánico y funcional de las partes que han sido desparramadas por la historia. Ya no se trata de coser (e intentar ocultar las costuras de) las imágenes que se han materializado por medio del gran revelador universal que sería el lenguaje, sino antes bien de compartir la des-unión, la deriva constelada de imágenes cuyos vínculos son los de la vecindad y que, en lugar de demandar una discursivización (una traducción a un logos inteligible),exigen la conexión generativa con otras tantas imágenes de procedencia ignota.

ahora si,

el cielo, la soga,

la piedra,

el mar.

ahora sí,

nos abrazamos a los huesos

enterrados

en el mar 
y nadie sabe que nacimos. que no nacimos.

atados a las piedras por esa muda libertad $(84-85)$

\section{Respiran las piedras, el sepulcro}

Los ancestros cuyos rostros guarda el poeta escondidos en el suyo son las piedras, fósiles de unos huesos, huesos de unos cadáveres, cadáveres de unos cuerpos adormecidos arrojados al mar. Pero de piedra también es el poema-sepulcro imposible de esos "huesos desesperados por amor» (7I), de esa madre "en cuatro abierta» (I5), de ese padre que «se desintegra/ no en mi casa»(67): trabajo de duelo transformado en monumento sepulcral, materialidad petrificada en la palabra inspirada — es decir, hablada y vivida por otros: «algo me vive» (73).

Refiriéndose a la metapsicología de Pierre Fédida, Didi-Huberman (2005) destaca el modo en que el psicoanalista sustituye el «trabajo del duelo» por una «obra de sepultura» (70-7I), es decir, un concepto económico conectado a un comportamiento (en el primer caso) por un concepto estético y un monumento (en el segundo caso). Pensando desde esta perspectiva la relación con unos ancestros que la memoria es incapaz de hallar, emerge la noción de reminiscencia bajo la forma de una imagen material, que Fédida llama «soplo de viento». Didi-Huberman enfatiza que en ella ya no se trata de la representación del ausente sino de la representación pulverizada, es decir, de un polvo mineral que emana de la ausencia misma: una «sepultura sensorial» de la ausencia donde la materia en movimiento adquiere toda su potencia genealógica (77-79). En este sentido, el poema/imagen «asume, pronuncia, acentúa, vuelve sensible una respiración otra» (72) y hace posible entonces una densificación que habilita el pasaje entre temporalidades no ya a través de la palabra como "valor simbólico» sino como materia en movimiento (77). Hay un soplo indistinto, exento de sentimentalismo porque es razón e-motiva: algo móvil que lleva hacia el exterior lo que no puede ser representado en el interior. La palabra dicha, soplada, es entonces emanación de una ancestralidad que ya no es un tesoro simbólico en busca de una hermenéutica del pasado sino una resonancia que toca, afecta, llega de otra parte, que inunda como un perfume (eventualmente nauseabundo) el espacio del poema.

Más allá, o más acá, de un comportamiento económico sobre el dolor de haber nacido del sexo de las piedras, esa «secreta manera de nacer» dice Araldi Oesterheld (58), acaso se nos permita pensar en su poema una obra/desobra de otra clase: un sepulcro sensorial que hace respirar a las piedras de las que es a su vez monumento mortuorio. Una tumba de piedras y para piedras surgidas del ejercicio alquímico que transforma la ausencia en materia y la palabra en escultura. 


\section{Notas}

${ }^{1}$ En efecto la construcción agambeniana de la teoría del sujeto como testimonio a partir de un proceso de subjetivación y desubjetivación se deriva en gran medida de la experiencia del yo poético de Keats - tal como se narran en la carta a John Woodhouse-, de Rimbaud, Dante Alighieri o la heteronimia de Pessoa. Cfr. Agamben (I998:8I-I26) y Agamben (1996:93).

${ }^{2}$ Cfr. Yates.

${ }^{3}$ Sobre el problema de lo inefable, Semprún escribe «Lo inefable no es más que una coartada o una señal de pereza» (26). Véase también Didi-Huberman (2003) y Nancy (Io). Agamben señala el origen etimológico de la palabra "eufemismo»: observar en silencio religioso (1998:30). A su vez, repudia la adoración mística que parece surgir de las proclamas de incomunicabilidad del genocidio (2004:48).

${ }^{4}$ Acerca de la caracterización del poema como katechon, aunque en otro sentido que el aquí propuesto, cfr. Agamben (1996:I18).

${ }^{5}$ Vale recordar aquí que en el amplio campo de estudios acerca de la memoria traumática, en los últimos 20 años, aproximadamente, se ha abierto una disputa en torno a las características de la «memoria de $2^{\circ}$ generación», especialmente en cuanto a los modos en que se da en el ámbito artístico (y sobre todo, audiovisual). Una de las categorías más circulantes es la de posmemoria, acuñada por Marianne Hirsch en ocasión de los testimonios de familiares de víctimas de los campos de exterminio nazis (cfr. Hirsch 1992, 1997). En Argentina, hay una elevada producción teórica de dicha dimensión de la memoria que intenta pensar, a su vez, una profusa producción artística referida a las desapariciones forzadas de personas durante el terrorismo de Estado. En términos de estudios culturales, las derivas de este debate giran alrededor de las articulaciones que se dan entre política, historia y subjetividad. Es conocida la intervención de Sarlo, sobre todo, respondiendo a la introducción del término posmemoria. De acuerdo a la pensadora argentina, se trata de una categoría superflua que no tiene la suficiente especificidad como para delimitar un campo conceptual propio que le daría entidad. Para una reflexión más amplia de las relaciones entre memoria (del horror) y arte, con espe- cial hincapié en los casos de Argentina y Latinoamérica, queremos destacar la alta calidad de las investigaciones compartidas en el marco de las diferentes ediciones del Seminario Internacional Politicas de la Memoria organizado por el Centro Cultural Haroldo Conti (Espacio para la Memoria y la Promoción de los Derechos Humanos Ex ESMA). Allí, entre los años 2008 y 20I5, se han congregado teóricos, artistas y un público ávido de materiales nuevos para pensar la memoria reciente. Las actas de la mayoría de los encuentros pueden encontrarse en: http:// conti.derhuman.jus.gov.ar/areas/ep/seminarios.shtml

6 Sobre el desdoblamiento esencial que dispersa el origen, su relación con la palabra y, sobre todo, con la poesía, véase Blanchot (1955:255-256).

7 Es el poeta ruso Vadim Kozovoï (que residió en Francia desde 1981, después de haber pasado cinco años detenido en el campo de reclusión de Mordovia por «propaganda anti-soviética») quien escribió acerca del simún: «en ese punto de tangencia, sobre la mejilla perforada por el ardor, voy a librarme a las llamas, exaltaré a mi hermano el simún para arrancar, grano por grano, uñas y dientes de tristeza, todo tu chirriante desierto refractario, de este lado, desertor, del beso» (49). El simún es un «viento venenoso» (según la lengua árabe) de altísima temperatura, que sopla en el desierto del Sahara, un «viento rojo» cuyas ráfagas de arena hirviente lastiman, asfixian y matan a los seres vivos alcanzados.

8 Sobre las dos memorias, véase Agamben (2006:6I-62).

${ }^{9}$ En La escritura del desastre, Blanchot escribe: «Si el olvido precede a la memoria o tal vez la funda o no tiene parte en ella, olvidar no sólo es una falta, un defecto, una ausencia, un vacío (a partir del cual recordaríamos, pero que, en el mismo momento, sombra anticipadora, tacharía el recuerdo en su posibilidad misma, devolviendo lo memorable a su fragilidad, la memoria a la pérdida de memoria): el olvido, ni negativo ni positivo, sería la exigencia pasiva que no recibe ni quita el pasado, sino que, designando en él lo que nunca tuvo lugar (como en el por venir lo que no habrá de hallar su lugar en un presente), remite a formas no históricas del tiempo, a lo otro de los tiempos, a su indecisión eterna o eternamente provisoria, sin destino, sin presencia.» (1980:I34-I35). 
10 En este sentido, pueden leerse las palabras de Blanchot: «Suponemos que el olvido trabaja a la manera de lo negativo para restaurarse como memoria, memoria viva y revivificada. Así es. Puede ser de otra manera. Mas de todos modos, si separamos atrevidamente el olvido del recuerdo, buscamos todavía un efecto de olvido (efecto cuya causa no es el olvido), una especie de elaboración oculta y de lo oculto que se mantendría a distancia de lo manifiesto y que, identificándose con esta misma distancia (la no identidad) y manteniéndose como no manifiesta, tan sólo serviría para la manifestación; lo mismo que lethe acaba triste, gloriosamente en aletheia. El olvido inoperante, para siempre desobrado, que no es nada y no hace nada (al que ni siquiera alcanzaría el morir), esto es lo que, sustrayéndose tanto al conocimiento como al desconocimiento, no nos deja tranquilos, sin inquietarnos, ya que lo recubrimos con la inconsciencia-conciencia» (I980:I35).

11 «En el texto que acabamos de comentar, Kafka escribe "Nunca he podido comprender que fuera posible o casi, para quien quiera que deseara escribir, el objetivar el dolor en el dolor". La palabra objetivar llama la aten- ción porque la literatura tiende precisamente a construir un objeto. Objetiva el dolor al constituirlo en objeto. No lo experimenta, lo hace existir de otro modo, le da una materialidad que no es ya la del cuerpo, sino la materialidad de las palabras por las cuales es significada la conmoción del mundo que el sufrimiento pretende ser. Semejante objeto no es necesariamente una imitación de los cambios que el dolor nos hace vivir: él se constituye para presentar al dolor, no para representarlo; en principio, es preciso que este objeto exista, es decir, que sea un total siempre indeterminado de relaciones determinadas; dicho de otra manera, que haya en él, como en toda cosa existente, siempre una excedencia de la cual no sea posible dar cuenta» (Blanchot 1949:28).

12 «La imagen poética, en esta ausencia misma de la cosa, pretende restituirnos el fondo de su presencia, no su forma — que es lo que se ve-, sino su parte inferior — que es lo que se penetra_-, su realidad de tierra, su "materia-emoción". En esta nueva presencia, la cosa pierde su individualidad de objeto cerrado por el uso, tiende a metamorfosearse en una cosa completamente diferente.» (Blanchot 1949:II2).

\section{Bibliografía}

agamben, giorgio (1996). Categorie italiane. Studi di poetica. Venezia: Marsilio.

(1998). Quelche resta di Auschwitz, L'archivio e il testimone, Homo sacer III. Torino:

Bollati Boringhieri.

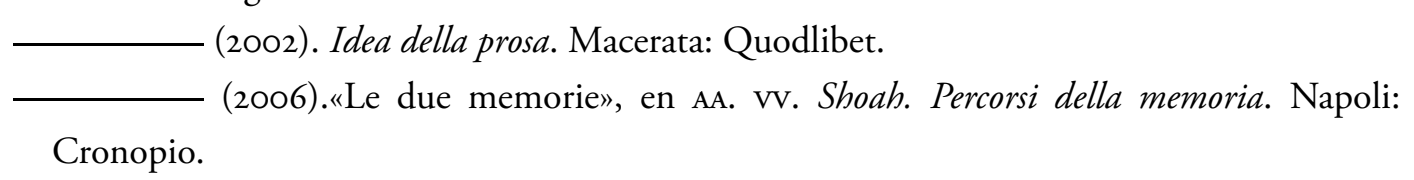

ARALDi OeSterheld, FERnANdo (20I4). El sexo de las piedras. Buenos Aires: Mansalva.

Blanchot, MAURICE (1949). La part du feu. París: Gallimard.

(1955). L'Espace littéraire. París, Gallimard, I962.

(I980). L'écriture du désastre. París: Gallimard.

DIDI-HuBERMAN, GEORGES (2003). Imágenes pese a todo. Memoria visual del Holocausto. Barcelona:

Paidós, 2004. Traducción de Mariana Miracle.

(2005). Gestes d'air et de pierre. París: Minuit.

FOUCAUlT, MICHEL (1969). Las palabras y las cosas. Una arqueología de las ciencias humanas.

Buenos Aires: Siglo XxI, 20I4. Traducción de Elsa Cecilia Frost.

HIRSCH, MARIANNE (I992-I993). "Family pictures: Maus, Mourning and Post-Memory».

Discourse: Journal for Theoretical Studies in Media and Culture 15(2), 3-29. 
(1997). Family Frames: Photography, Narrative, and Postmemory. Cambridge/

Londres: Harvard University Press.

Kozovö̈, vadim (1984). Hors de la colline. París: Hermann.

lacoue-labarthe, philippe (1988). La ficción de lo politico, Heidegger, el arte y la política.

Madrid: Arena, 2002. Traducción de Miguel Lancho.

NANCY, JEAN-LUC (200I). La representación prohibida. Buenos Aires: Amorrortu, 2005. Traducción

de Margarita Martínez.

SARLO, BEATRIZ (2005). Tiempo pasado: cultura de la memoria y giro subjetivo: una discusión.

Buenos Aires: Siglo XxI.

SEMPRÚN, JORGE (1994). La escritura o la vida. Buenos Aires: Tusquets, 2004. Traducción de

Thomas Kauf.

warburg, ABy (2003). Atlas Mnemosyne. Madrid: Akal, 20io. Traducción de Joaquín Chamorro

Mielke.

yates, fRANCES (1966). El teatro de la memoria. Madrid: Siruela, 2005. Traducción de Ignacio

Gómez de Liaño. 